\title{
100 voces y expresiones del español de Valencia en el aula de E/LE
}

\author{
DAVID GIMÉNEZ FOLQUÉS \\ Universitat de València \\ david.gimenez-folques@uv.es
}

\begin{abstract}
Resumen: Resulta recurrente en el aula de E/LE preguntarse qué variante del español enseñar. Por un lado, es importante que los estudiantes se familiaricen con la realidad dialectal panhispánica, donde pueden encontrarse con diferentes variantes del español; pero, por el otro, también es interesante que conozcan las peculiaridades del español de la zona donde están llevando a cabo su aprendizaje lingüístico. De este modo, en el presente trabajo trataremos de explicar las características del español de Valencia mediante su léxico, en concreto, mediante 100 voces y expresiones extraídas de corpus significativos como el de Val.Es.Co, PRESEVAL o CORPES. Finalmente, incluiremos una breve propuesta didáctica que sirva como muestra.
\end{abstract}

Palabras clave: variedades del español, español de Valencia, corpus españoles.

\begin{abstract}
It is relevant to know what Spanish variant we have to teach in E/LE class. On the one hand it is important that students have knowledge learn about the reality of the Spanish language. On the other hand, it is also important that they learn the Spanish variant from the context where they are studying. Therefore, we will explain the characteristics of the Valencian Spanish, using 100 words and expressions extracted from Val.Es.Co, PRESEVAL and CORPES corpora. Finally, we will include a brief didactic proposal.
\end{abstract}

Key words: Spanish variants, Valencian Spanish, Spanish corpus. 


\section{Introducción}

La lengua española supone un ente heterogéneo en forma de diferentes variedades dialectales, tanto en España como en América. Estas variantes conllevan diferencias léxicas, fonéticas, morfosintácticas e incluso pragmáticas, como señalan Aleza y Enguita (2010). Aunque es cierto que en el nivel léxico encontraremos mayor diversidad, con respecto a los otros niveles.

Este contexto dialectal está presente en las clases de E/LE, ya que el profesor debe tomar una decisión sobre qué variedad del español escoger para llevar a cabo este aprendizaje. Si bien resulta importante transmitir el conocimiento de esta variedad panhispánica a nuestros alumnos, también sería interesante que aprendieran las características lingüísticas del contexto donde se encuentran.

En primer lugar, como acabamos de mencionar, nos aseguraremos de que nuestros alumnos conozcan cuál es la situación del español, ya que de esta manera evitarán conflictos lingüísticos cuando viajen a otra zona panhispánica distinta de aquella donde han aprendido español. En segundo lugar, para completar esta tarea dialectal, los alumnos, mientras estudian en una zona concreta del ámbito panhispánico, agradecerán, en su vida diaria, la enseñanza de las principales características lingüísticas de este contexto.

Por este motivo, en el presente trabajo pretendemos acercarnos a la variante del español en Valencia mediante una selección léxica de voces y expresiones, extraídas de los principales corpus del español que investigan, también, esta variante de la Comunidad Valenciana. Estos corpus serán el de Val.Es.Co ${ }^{1}$ (Valencia Español Coloquial), PRESEVAL $^{2}$ (Proyecto para el Estudio Sociolingüístico del Español de Valencia) y el CORPES $^{3}$ (Corpus del Español del Siglo XXI). A partir de estas fuentes, hemos seleccionado voces o expresiones de amplio uso en la Comunidad Valenciana y, especialmente, en Valencia ciudad. Así mismo, no únicamente incluiremos aquellas formas lingüísticas que tengan un origen valenciano, sino también aquellas palabras o expresiones que se utilizan con una acepción diferente o con un mayor uso con respecto a otras zonas dialectales del español ${ }^{4}$.

Por otro lado, podríamos encontrarnos con la polémica que envuelve al binomio «propio-normativo ${ }^{5} »$. Como indican Enguita y Aleza (2010) existen rasgos específicos en las zonas dialectales del español que, además, sirven como elementos diferenciales con respecto al resto de variantes. Otra cosa sería ver si estos rasgos son normativos o, en su defecto, están permitidos según los criterios de la RAE (Real Academia Española)

\footnotetext{
${ }^{1} \mathrm{http}: / / \mathrm{www}$. valesco.es/?q=es/corpus.

${ }^{2} \mathrm{http}: / /$ www.uv.es/preseval/ppal.htm.

${ }^{3} \mathrm{http}: / /$ web.frl.es/CORPES/view.

${ }^{4}$ De entre todos los ejemplos extraídos, incluiremos en este trabajo las 100 voces y expresiones más extendidas, según la frecuencia de uso que indican los corpus.

${ }^{5}$ En el mundo panhispánico actual resulta muy complicado hablar de variante o elemento «normativo», ya que la misma heterogeneidad de la lengua española complica la definición. Aun así, en un intento de agrupar variantes, la RAE y, desde una perspectiva más amplia, la ASALE hablan de la doble norma hispánica, que trata del español continental (entre otros rasgos con un consonantismo fuerte) y del español atlántico (con un consonantismo débil). Este contexto es del que se sirven estos organismos para asentar el español estándar, llevado a la práctica con las distintas obras que publican (diccionarios, ortografías y gramáticas).
} 
y la ASALE (Asociación de Academias de la Lengua Española). Por lo tanto, consideramos relevante cotejar con el DLE (2014) si estas formas que presentamos están o no incluidas en esta última edición del Diccionario.

Finalmente, realizaremos una breve propuesta didáctica para comprobar cómo podríamos llevar esta realidad al aula. Esta propuesta práctica se basará en la investigación realizada sobre el léxico extraído de los corpus.

\section{El español de Valencia}

Como sabemos, en la Comunidad Valenciana existe una situación de bilingüismo entre el valenciano y el español. A partir de este contexto, se produce un escenario de contacto lingüístico, especialmente en aquellos hablantes que son bilingües. De este modo, cuando uno de estos hablantes usa el español recibe influencia fonética, morfosintáctica y léxica del valenciano. Ante este fenómeno, se produce una nueva variante del español, ya que esta forma lingüística contiene rasgos propios que la diferencian de las otras variantes.

Autores como Briz (2004), Gómez Molina (1996) y Casanova (1996) reivindican esta variedad del español como legítima y hablan de sus características específicas como, por ejemplo, variaciones en la entonación y acentuación, cambios de género y concordancia, modificación en el sistema verbal y, finalmente, préstamos del valenciano hacia el español, ámbito, por otro lado, que centrará nuestro interés en la presente investigación.

Pese a estas referencias, no es hasta los años 90 cuando se investiga con mayor profundidad sobre esta variante del español. Es en los últimos años, como acabamos de observar en las obras anteriores, cuando los estudios sobre el castellano de la Comunidad Valenciana empiezan a surgir; además de los correspondientes en las zonas de Cataluña y las Islas Baleares.

Junto con las obras señaladas, trabajos que tratan la variante del español en la Comunidad Valenciana serían los de Lapesa (1996), Seco (1989), Blas Arroyo (2004), Cano Aguilar (2004) y Sinner y Wesch (2008), entre otros. En todas estas obras podemos observar cómo es el nivel léxico el que experimenta una mayor variación cuando se produce este contacto lingüístico.

En cuanto al origen y al trazado lingüístico actual de la Comunidad Valenciana, Briz (2004) señala que son las cuestiones históricas las que influyen a la hora de hablar del perfil que toma esta variante, según exista un predominio valenciano o castellano. Así, «predomina el valenciano en zonas que fueron repobladas por catalanes, y el castellano en territorios cuyos repobladores procedían de Aragón, La Mancha, Murcia, etc.» (Briz, 2004: 119). Por otro lado, el autor señala que el valenciano se utiliza especialmente en el ámbito familiar y el castellano en el ámbito laboral y comunicativo, con lo cual se produce una situación de diglosia a favor de esta última lengua.

De este modo, tendremos que tener en cuenta este contexto, ya que la intensidad del uso de una u otra lengua dentro de este contacto lingüístico puede variar el resultado, según la zona a la que nos refiramos; además, contamos con el factor del grado de bilingüismo del hablante, como hemos señalado en apartados anteriores, que también determinará el nivel de influencia del valenciano hacia el castellano. 
En último lugar, Briz señala otro parámetro como determinante para que la influencia del valenciano sobre el castellano sea mayor o menor, es decir, el del registro utilizado, ya que «en la interacción coloquial es donde más frecuentemente se producen y más auténticamente se manifiestan los hechos lingüísticos derivados del contacto» (2004, 128).

\section{Metodología}

Como hemos observado, el español hablado en Valencia pertenece a una variante reconocida y reivindicada por diferentes investigadores. Ante esta realidad, aquellos alumnos de E/LE que lleguen a Valencia se encontrarán con esta variante $\mathrm{y}$, por lo tanto, sería pertinente enseñarles sus rasgos generales, como, por ejemplo, qué palabras y expresiones pertenecen propiamente a esa forma lingüística.

De este modo, nuestro objetivo es el de proponer una selección léxica, en concreto 100 ejemplos entre voces y expresiones, para llevarla al aula. Para realizar esta selección léxica nos hemos valido de corpus que estudian completa o parcialmente el español de Valencia, como es el caso de los corpus Val.Es.Co, PRESEVAL y CORPES. Seleccionaremos únicamente aquellas voces que contengan una mayor frecuencia de aparición.

\subsection{Corpus 2.0 del Grupo Val.Es.Co}

El Grupo Valesco de la Universitat de València, originario del Departamento de Filología Española, ha creado un corpus digitalizado gratuito del español coloquial en Valencia. En este corpus se pueden realizar búsquedas por conversaciones, intervenciones, grupos entonativos o palabras, fragmentados de la siguiente manera:

-46 conversaciones

-12.976 intervenciones

•29.205 grupos de entonación

$\bullet 120.246$ palabras.

\subsection{CORPES}

Corpus del Español del Siglo XXI de la Real Academia Española. Está formado por miles de textos del ámbito panhispánico, de los que una parte importante son transcripciones de conversaciones y discursos. Este corpus resultaba significativo, ya que el español de Valencia aparece entre las variantes analizadas. En la búsqueda léxica existen parámetros geográficos que hemos utilizado para acotar los resultados hacia la zona que nos interesaba.

\subsection{Corpus del PRESEVAL}

Corpus dirigido al estudio del español hablado en Valencia. Los hablantes que aparecen en las conversaciones y transcripciones son autóctonos o residentes de larga permanencia y con conciencia de pertenecer a esta comunidad de habla. Resulta 
interesante que en el etiquetado de las conversaciones aparezca el origen, la edad, el domicilio, el grado de instrucción, la profesión, la lengua materna y un último apartado de observaciones. Todos estos datos ayudan a realizar un estudio homogéneo y significativo sobre esta variante del español

\section{El corpus resultante dividido por temática}

A partir de los corpus que acabamos de ver, y acotando los parámetros a la zona del español de Valencia, hemos extraído el listado de palabras que pasamos a detallar, por ámbitos temáticos, a continuación.

\subsection{Gastronomía}

Arroz a banda, alioli, butifarra, fideuá, paella, paellero/a, socarrar, torrar (asar), clóchina, tellinas, mero, piñol, coca (torta), sucar (mojar), parar la mesa (poner la mesa), restregar (untar), esgarraet, rosquilletas, garrofó, pilota, all i pebre, fartons, corfa, entrepán, tramusos, picaeta.

\subsection{Festividad}

Tomatina, ninot, ninot indultat, falla, foguera, mascletá, cremá, despertá, cridá, plantá.

\subsection{Estado de ánimo}

Encantado (atónito), estar destemplado (alternancia de temperatura corporal), desficioso (nervioso, desesperado).

\subsection{Expresiones e interjecciones}

Che, mone (vamos), nano (tío), au (vamos).

\subsection{Acciones con el verbo «hacer»}

Hacerse mal (hacerse daño), hacer miedo, hacerse un café, hacer vacaciones, hacer la mano (fastidiar), hacerse el pelo (peinarse), hacer las cosas arreu (hacer las cosas de cualquier manera), hacer bien (quedar bien), hacer sol.

\subsection{Otras locuciones}

Dar pena (molestar), saber mal (sentirse mal, sentir culpa), ir a pegar una vuelta, ir mudado (ir bien vestido), ser preciso (ser necesario), pelarse (evadir una responsabilidad).

\subsection{Hogar}

Mocho, deslunado, banco de la cocina, terrao (terraza) / terrado (terraza), enchufar la luz, finca (edificio), rachola (ladrillo), palometa (percha). 


\subsection{Organizaciones, monumentos y artistas valencianos}

Generalidad, Conselleria, Lonja, sorollista (Sorolla), blasquista (Blasco Ibáñez), sorollismo, blasquismo.

\subsection{Otros}

Comboi (ilusión), convoyado (ilusionado), camal (pernera), chafar (pisar), encalar (hacer que un objeto quede atascado en altura o lugar fuera de alcance ${ }^{6}$ ), caler, empastrar (manchar), choparse (mojarse), olorar, chepa, la calor (cambio de género), chiquito, yayo/a, bonico/a, fava (tonto/a), faena, pudent (podrido), bandarra (sinvergüenza), paraeta (tiendecita), engañarse (equivocarse), espolsarse (sacudirse), churro (persona que no habla valenciano en la Comunidad Valenciana), escampar (irse de un lugar), mamprender (echar la bronca), agonía (ganas de vomitar), renegar (reñir).

\section{Filtro del $D L E$ (Diccionario de la lengua española)}

Mediante la comprobación de si las voces o expresiones aparecen en el $D L E$, tendremos un parámetro para poder medir hasta qué punto esta variante es reconocida por la Real Academia Española o no. Hay que tener en cuenta que la Academia sigue diferentes parámetros para la inclusión de voces en su Diccionario como, por ejemplo, extensión de uso en una zona o conjunto de zonas, o temporalidad.

Por otro lado, el Diccionario no incluye palabras con grafías ajenas al sistema lingüístico en español si no es en cursiva, marcando, entonces, que es un préstamo perteneciente a otra lengua.

\subsection{No aparecen en el $D L E$}

Estar destemplado, ir mudado, desficioso, desfici, hacer las cosas arreu, comboi, convoyado, camal, patio de una casa, deslunado, el banco de la cocina, enchufar la luz, terrao, ir a "pegar" una vuelta, Conselleria, sorollista, blasquista, sorollismo, blasquismo, tomatina, nano, au, mone, empastrar, choparse, hacerse el pelo, pelarse, preciso (es), clóchina, rachola, saber mal, hacerse mal, hacerse un café, hacer vacaciones, hacer miedo, hacer la mano, hacer sol, olorar, piñol, sucar, parar la mesa, dar pena, mascletá, cremá, despertá, hacer bien, la calor, esgarraet, rosquilletas, garrofó, pilota, all i pebre, fartons, plantá, chiquito, bonico/a, fava, palometa, pudent, paraeta, corfa, espolsarse, entrepán, escampar, mamprender, tramusos, picaeta, agonía.

\subsection{Aparecen en el $D L E$}

Mocho, terrado, chafar, restregar, encalar, arroz abanda, alioli, butifarra, che, fideuá, caler, falla, foguera, Generalidad, Lonja, paella, ninot, ninot indultat, paellero/a,

\footnotetext{
${ }^{6}$ http://dle.rae.es/?id=ExLP6To|ExMUTLM.
} 
socarrar, finca, torrar, tellinas, mero, chepa, encantado, coca, yayo/a, faena, bandarra, engañarse, churro, renegar.

Resumiendo, podemos observar que de los 100 ejemplos que hemos extraído, 33 han sido recogidos por el $D L E$, con lo cual el porcentaje de inclusión es bastante alto: según los datos, el $33 \%$ de los resultados encontrados. De este modo, estamos hablando de una variante que realmente tiene cabida en los organismos normativos de la lengua española.

\section{Propuesta didáctica}

A continuación, propondremos una breve propuesta didáctica, ya que, como profesores, debemos evitar dar a nuestros estudiantes listados léxicos para aprender esta variante, debido a que en ese caso los aprenderían de memoria o no les prestarían mucha atención $\mathrm{y}$, por lo tanto, el aprendizaje no sería significativo.

Conviene, así mismo, incluir actividades que sean didácticas, lúdicas y dinámicas. Por otro lado, se pueden enseñar en cualquier nivel educativo, ya que simplemente adaptando la actividad a la dificultad de nuestro curso la haremos apta para el mismo.

Por ejemplo, en la primera propuesta «completar huecos», tenemos un ejercicio recomendado para niveles avanzados, ya que requiere el entendimiento del contexto y de los registros, aunque podríamos trabajarlo en niveles inferiores si orientamos al alumno, dándole el significado de las expresiones, y ponemos un contexto más sencillo en las frases.

En la segunda propuesta «menú gastronómico», tenemos un ejercicio apto para niveles intermedios. En niveles iniciales e intermedios simplemente les pedimos a nuestros estudiantes que señalen las palabras que se usan en el español de Valencia y expliquen qué significan. En niveles intermedios altos y avanzados les podemos pedir que aporten un esfuerzo creativo a la actividad, como, por ejemplo, crear ellos mismos un menú con gastronomía valenciana.

En la tercer propuesta «texto fallero», al encontrarnos con un texto el margen de adaptación es amplio. En niveles iniciales, el profesor señalará directamente las palabras que pertenecen al español de Valencia. En el resto de niveles, pediremos que sean los alumnos los que encuentren y comenten las palabras o expresiones.

\subsection{Completar huecos}




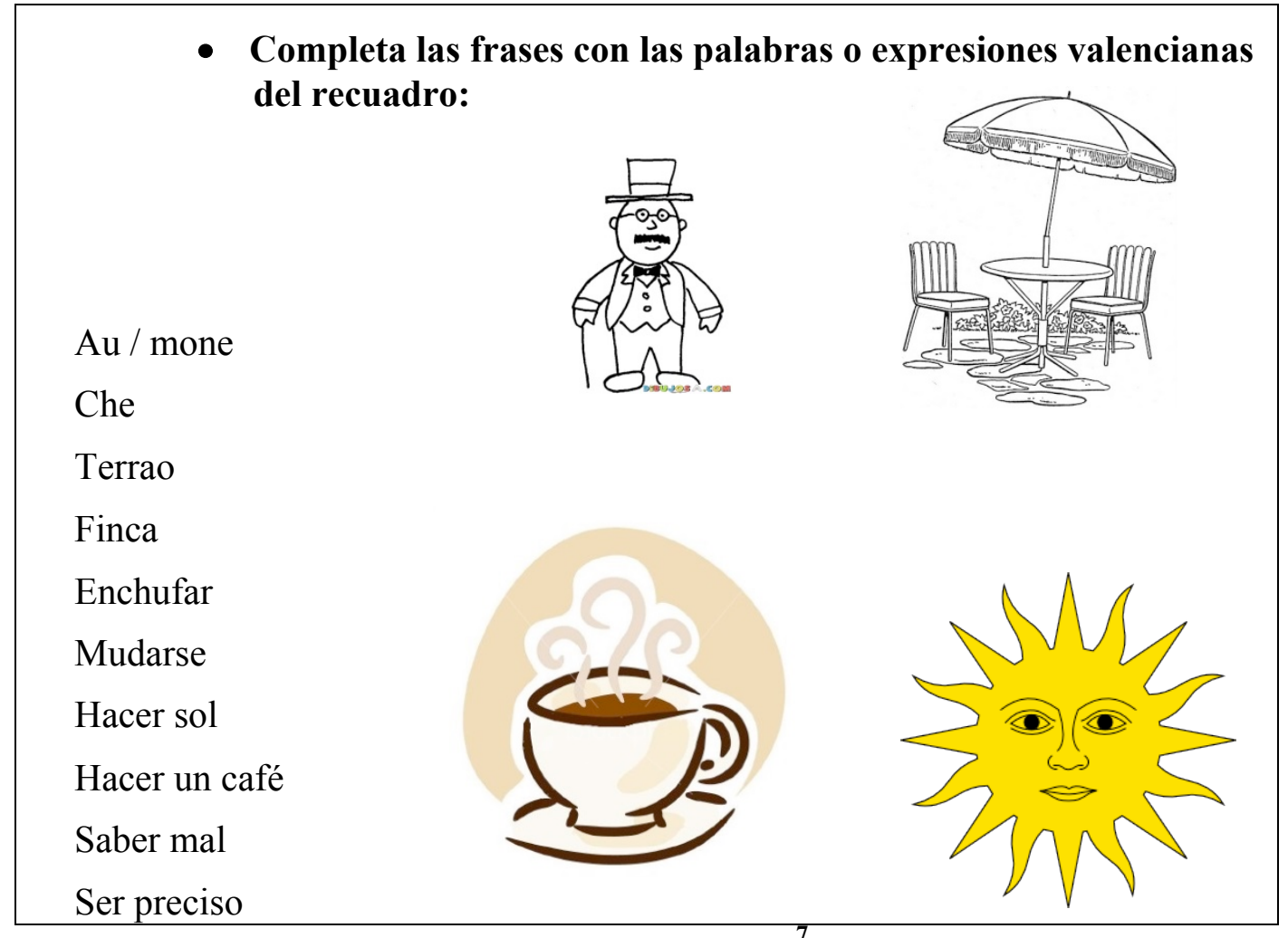

Figura 1. Ejemplo de ejercicio ${ }^{7}$

a) que estudies más, de otro modo no aprobarás.

b) i__ , nano!, ¿pero qué has hecho? Lo has tirado todo por el suelo.

c) i_ ! Si no llegaremos tarde.

d) Mira qué más amplio para salir a comer con el buen tiempo, además la tiene buena infraestructura.

e) ¿Te gustaría que nos ? Me gustaría que nos juntáramos, ya que hace mucho tiempo que no nos vemos.

f) Si no te importa , esto está muy oscuro.

g) Me he para salir, sabes que me gusta ponerme guapo.

h) $\mathrm{Me}$ haber contado su secreto, creo que se enfadará conmigo.

i) Podemos salir porque , no como ayer que llovió todo el día.

\subsection{Menú gastronómico}

- Lee el siguiente menú y extrae todas las palabras propias del castellano de la Comunidad Valenciana:

\footnotetext{
${ }^{7}$ Imágenes extraídas de:

http://dibujosa.com/index.php?codigo=9026, http://dibujoheraldico.blogspot.com.es/2011/10/sol-de-mayo.html, http://iescalderon.es/cartel-expo-comparte-copy_cr/, http://www.idibujosparacolorear.com/muebles-de-terrazapara-colorear.
} 


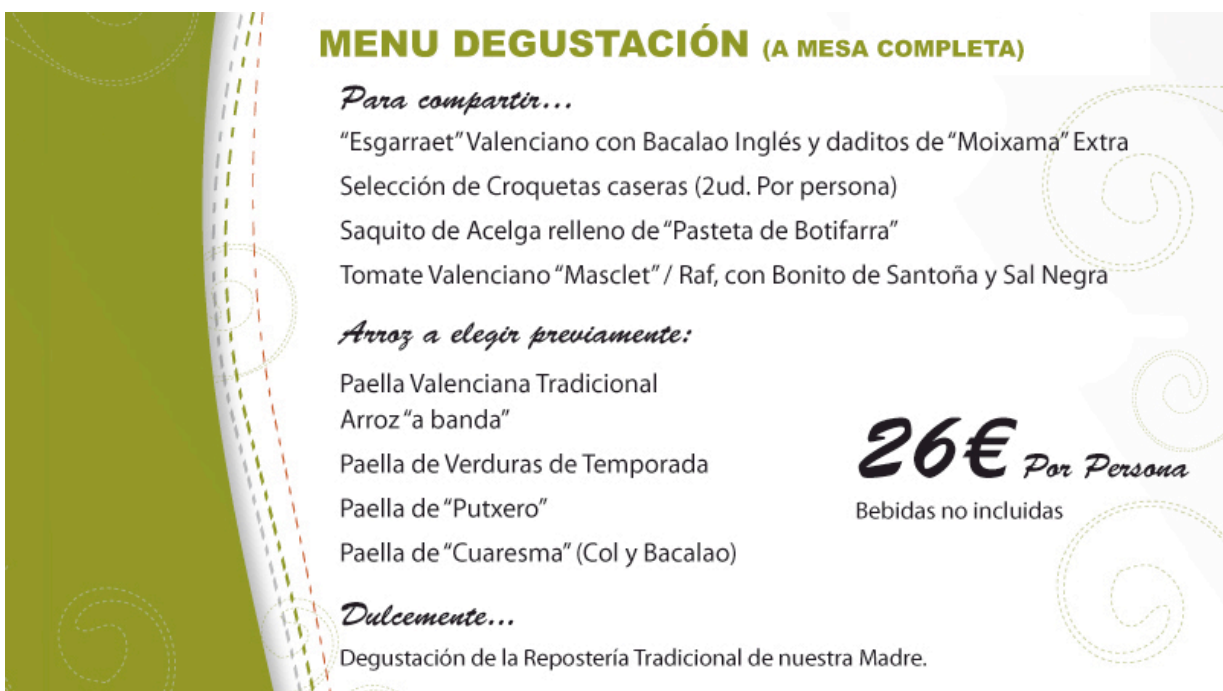

Figura 2. Menú

\subsection{Texto fallero}

\section{- Lee el siguiente texto sobre las fallas y extrae todas las palabras y expresiones propias del castellano de la Comunidad Valenciana}

\section{LAS CIFRAS DE LAS FALLAS 2017}

Los 6,97 millones de euros invertidos este año en los más de 770 monumentos que en unos días desplegarán por toda Valencia su sátira combustible y su arte efímero esperan su inexorable cita con el fuego de San José, en las que van a ser las primeras Fallas como Patrimonio Inmaterial de la Humanidad.

Valencia vive inmersa en el ambiente prefallero, con el estruendo diario de las mascletás y una actividad frenética en los talleres, donde los artistas afinan sus pinceles para ultimar cada detalle de los monumentos en los que vuelcan toda su creatividad y con los que alimentarán el fuego purificador en la Nit de la Cremà.

Mientras llega ese 19 de marzo, con el que se anuncia la llegada de la primavera, la ciudad toma impulso para adentrarse en la vorágine que traen las Fallas, envueltas en un ambiente festivo callejero y al que suele respetar el tiempo soleado primaveral.

La tiranía fallera traducida en cortes de cientos de calles, caos de tráfico y verbenas hasta horas intempestivas se compensa por la amalgama que forman los colores de los monumentos, el olor de los churros y buñuelos con chocolate, el sonido de los espectáculos pirotécnicos y las emociones de cada acto de Fallas.

Las de 2017 serán las primeras sin Rita Barberá, fallecida el pasado noviembre y que, aunque ya vivió en segundo plano sin ser alcaldesa el año pasado, siempre quedará ligada a la memoria colectiva del mundo fallero, con sus saltos en el balcón, su discurso del "caloret", tirando petardos o retratada en innumerables ninots.

Con la llegada de Joan Ribó al frente del Ayuntamiento, las Fallas de 2016 abrieron el balcón a los vecinos y este año sigue la iniciativa aunque se dobla a veinte el número de los que, por sorteo, podrá acceder cada día a ver la mascletà desde uno de los principales iconos de las fiestas josefinas (380 en total) $[\ldots]$

Precisamente la Crida es el siguiente acto fallero, en el que, desde el histórico escenario de las Torres de Serranos, se dio el inicio oficial a las primeras Fallas con el sello de la Unesco y en la que por primera

\footnotetext{
${ }^{8}$ Imagen extraída de: http://www.restaurantelevante.com/valencia/carta.html.
} 
vez los discursos estaban subtitulados para personas sordas.

Es el preludio de una fiesta que traerá un millón de visitantes durante los cinco día grandes, del 15 al 19 de marzo, especialmente por su coincidencia con fin de semana, y en la que los primeros días de la plantà se viven con la expectación e ilusión de ver qué monumento se corona como la mejor falla del año $[\ldots]$

Figura 3. Ejemplo de texto 9

\section{Conclusiones}

Como hemos podido observar, hay un gran número de voces y expresiones que son propias del español de Valencia; principalmente, las encontramos en ámbitos como el de la gastronomía («butifarra, clóchina, fartons, mero») o la festividad («falla, ninot, plantá»), entre otros.

Mediante la extracción de este listado léxico, obtenemos una prueba más de que el español de Valencia representa una variante del español válida e, incluso, podríamos decir normativa como para poder llevarla al aula de E/LE. Hablamos de variante normativa, ya que muchas de estas voces o expresiones ya están recogidas por el $D L E$, como sería el caso de «alioli», «falla» o «fideuá».

Muchos son los autores que reivindican esta variante del español, de hecho, como hemos señalado anteriormente, el mundo panhispánico forma un ente lingüístico heterogéneo que, entre otras características, entra en contacto con otras lenguas, como es el caso del español en Valencia. Por lo tanto, esta realidad se debe tener en cuenta a la hora de hablar del término «estándar».

En definitiva, todos estos datos demuestran que enseñar esta variante del español en la enseñanza de E/LE, u otra perteneciente al ámbito panhispánico, sería adecuado, ya que estamos hablando de una forma lingüística del español tan válida como cualquier otra.

\section{Bibliografía:}

Aleza IzQuierdo, M. y Enguita Utrilla, J. M. (coords.) (2010). La lengua española en América: normas y usos actuales. Valencia: Universitat de València.

Blas ARroyo, J. L. (2004). «El español actual en las comunidades del ámbito lingüístico catalán» en R. Cano Aguilar (ed.), Historia de la lengua española (pp. 10651086). España: Ariel.

BRIZ Gómez, A. (2004). «El castellano en la Comunidad Valenciana». Revista Internacional de Lingüística Iberoamericana (4), 119-129.

Cano Aguilar, R. (2004). Historia de la lengua española. España: Ariel.

Gómez MolinA, J. R. (1996). «La variación lingüística en el español hablado de Valencia» en A. Briz et alii (ed.), Pragmática y gramática del español hablado (pp. 7590). Zaragoza: Pórtico.

Casanova, E. (1996). «El castellà de València» en A. Briz et alii (ed.), Pragmática y gramática del español hablado (pp. 292-298). Zaragoza: Pórtico.

9 Texto extraído de: http://www.lasprovincias.es/fallas-valencia/201703/05/cifras-fallas-valencia-201720170305125220.html 
LAPESA, R. (1996). El español moderno y contemporáneo: estudios lingüísticos. España: Crítica.

Real ACAdEMia Española y Asociación de ACAdEMias de la Lengua EsPañola (2014). Diccionario de la lengua española. Madrid: Espasa.

SECO, M. (1989). Gramática esencial del español. Madrid: Espasa-Calpe.

SinNER, C. y Wesch, A. (eds.) (2008). El castellano en las tierras de habla catalana. Frankfurt: Iberoamericana. 